\title{
FTIR and Raman Spectral Research on Metamorphism and Deformation of Coal
}

\author{
Xiaoshi Li, ${ }^{1}$ Yiwen Ju, ${ }^{1}$ Quanlin Hou, ${ }^{1}$ Zhuo Li, ${ }^{2}$ and Junjia Fan ${ }^{3}$ \\ ${ }^{1}$ Key Laboratory of Computational Geodynamics, College of Earth Science, Graduate University of Chinese Academy of Sciences, \\ Beijing 100049, China \\ ${ }^{2}$ State Key Laboratory of Petroleum Resource and Prospecting, China University of Petroleum, Beijing 102249, China \\ ${ }^{3}$ Key Lab of Basin Structure and Petroleum Accumulation, PetroChina Research Institute of Petroleum Exploration and Development, \\ Beijing 100083, China
}

Correspondence should be addressed to Yiwen Ju, juyw03@163.com

Received 13 January 2012; Revised 17 April 2012; Accepted 17 April 2012

Academic Editor: Hongyuan Zhang

Copyright (C) 2012 Xiaoshi Li et al. This is an open access article distributed under the Creative Commons Attribution License, which permits unrestricted use, distribution, and reproduction in any medium, provided the original work is properly cited.

\begin{abstract}
Under different metamorphic environments, coal will form different types of tectonically deformed coal (TDC) by tectonic stress and even the macromolecular structure can be changed. The structure and composition evolution of TDC have been investigated in details using Fourier transform infrared spectroscopy and Raman spectroscopy. The ductile deformation can generate strain energy via increase of dislocation in molecular structure of TDC, and it can exert an obvious influence on degradation and polycondensation. The brittle deformation can generate frictional heat energy and promote the metamorphism and degradation, but less effect on polycondensation. Furthermore, degradation affects the structural evolution of coal in lower metamorphic stage primarily, whereas polycondensation is the most important controlling factor in higher metamorphic stage. Tectonic deformation can produce secondary structural defects in macromolecular structure of TDC. Under the control of metamorphism and deformation, the small molecules which break and fall off from the macromolecular structure of TDC are replenished and embedded into the secondary structural defects preferentially and form aromatic rings by polycondensation. These processes improved the stability of macromolecular structure greatly. It is easier for ductile deformation to induce secondary structural defects than in brittle deformation.
\end{abstract}

\section{Introduction}

The study of macromolecular structure and complicated composition of coal is the most difficult and important topic in coal chemistry [1-4]. Effective analytical methods for coal structure and chemical composition research, such as Fourier transform infrared (FTIR) spectroscopy and Raman spectroscopy are, becoming more and more important for coal chemical researchers [5-15]. Previous studies discussed that with the upgrade of metamorphism, the aromatic structure of primary structure coal increased and expanded, whereas the side chain of aliphatic compound and functional group decreased. The hydrogen and oxygen deplete in coals; as a result, the condensation degree gradually improved. Aromatic structure is mainly composed of anthracite, and the condensation degree is further improved $[2,3,5$,
16, 17]. The coal basins in China experienced multiple tectonic movements and developed widely distribution of tectonically deformed coal (TDC) under the strong tectonic deformation environments [18]. Compared with primary structure coal, the evolution characteristics and ways of macromolecular structure of TDC are more complicated $[8,17-21]$. The formation of lignite due to diagenesis could experience different degrees of metamorphism under various temperature-pressure conditions during geological history. If the coal seams are apparently affected by tectonic stress, they can produce deformation in certain degrees. For all the deformational coal seams, the process and mechanism of deformation (brittle deformation and ductile deformation) are actually different [17-21]. Many studies have been conducted in order to investigate the relationship between the group absorption frequency of FTIR and the 
metamorphic grade of coals, as well as Raman spectral analysis on carbon materials [3-15, 19]; however, products about the studies of different deformation mechanisms and grades of TDC using FTIR and Raman spectrum analysis, and the analysis of evolution process and mechanisms in macromolecular structure of TDC, were rarely reported. Different deformation mechanisms will exert different influences on the macromolecular structure and composition of TDC $[6,7,18,19]$. Based on the FTIR and Raman spectrum analysis of TDC samples from Huaibei coalfield, the evolution characteristics of macromolecular structure affected by the change of metamorphism and deformation grade are discussed. The aim of this paper is to explain the mechanism of tectonic deformational influence on the evolution of structural defects and chemical composition.

\section{Samples and Experimental Methods}

The TDC samples with different deformation and metamorphism $\left(0.7 \%<R_{\mathrm{O} \text {, max }}<3.1 \%\right)$ were collected from PermoCarboniferous coal bed in Huaibei coal field, which was strongly affected by the Mesozoic tectonic deformation. The coal seams were mainly distributed in graben, especially in syncline. The tectonic deformation altered the structure of coal seams remarkably and formed various types of TDC.

All samples are pretreated through demineralization and vitrinite centrifugation processes in order to better delineate the characteristics of the deformation and metamorphism of TDC samples. The demineralization process utilized $\mathrm{HCl}$ and $\mathrm{HF}$ to reduce the proportion of mineral matter in each sample $(<2 \%)$. The vitrinite centrifugation process used benzene and $\mathrm{CCl}_{4}$ to increase the composition percentage of vitrinite to $80-90 \%$. The group maceral and vitrinite reflectance $\left(R_{\mathrm{O}, \max }\right)$ were tested as well.

The FTIR analysis on 32 samples and Raman analysis on 19 samples are conducted to further understand the evolution of macromolecular structure affected by deformation and metamorphism. It can be determined that the type of functional group and its change correlated with deformation and metamorphism in coal by analysis of absorption band, shown on infrared spectrum [7,9]. The structural analysis and qualitative identification of molecular can be studied by Raman spectrum because the formation of Raman spectra is closely connected with the structure and the ordering degree of coal macromolecule [22]. FTIR was performed on Nicolet 750 microscopic infrared spectrometer in the Analytical Instrumentation Center in Peking University. The scan ranges from $4000 \mathrm{~cm}^{-1}$ to $650 \mathrm{~cm}^{-1}$. Spectra were recorded by coadding 128 scans at a resolution of $8 \mathrm{~cm}^{-1}$ using an MCT/A detector and a $\mathrm{KBr} / \mathrm{Ge}$ beam splitter. Raman was performed on Renishaw RM-1000 microscopic Raman spectrometer at the State Key Laboratory of Geological Processes and Mineral Resources in China University of Geosciences. The spectral resolution was $2.4 \mathrm{~cm}^{-1}$, spit width was $2.5 \mathrm{~cm}^{-1}$, and laser power on the sample surface was $0.8 \mathrm{mw}$; measurements were carried out using the $514.5 \mathrm{~nm}$ excitation wavelength with $\mathrm{Ar}^{+}$laser; acquisition time was $30 \mathrm{~s}$. The spectra were measured under $25^{\circ} \mathrm{C}$ temperature.

\section{Results and Analysis}

Part of experiment results are listed in Table 1.

3.1. Parameter of FTIR Analysis. The types of functional group in TDC samples collected from Huaibei coal field are basically the same with other researchers $[3,7,23]$. But the peak positions and the changes of absorption peaks with the increase of metamorphic grade are different from others (Figure 1). The biggest difference between TDC and the primary structure coal showed on FTIR spectrum is reflected in the change of relative absorption strength but not the absorption frequency.

\subsubsection{Evolution of Characteristic Frequency of Aromatic} Structure. The characteristic frequency of aromatic structure includes the absorption strength of (1) $3049 \mathrm{~cm}^{-1}$ related to stretching vibration of $\mathrm{CH}$ in aromatic ring, (2) $1600 \mathrm{~cm}^{-1}$ related to vibration of $\mathrm{C}=\mathrm{C}$ in aromatic ring, and (3) $749 \mathrm{~cm}^{-1}, 810 \mathrm{~cm}^{-1}$, and $871 \mathrm{~cm}^{-1}$ related to the plane deformation vibration of $\mathrm{CH}$ in aromatic rings. With the increase of metamorphic grade, the absorption strength of $1600 \mathrm{~cm}^{-1}$ has little change in brittle deformational coal but decreases first and increases later in ductile deformational coal, and with the range from 0.994 to 1 (Figure 2(a)).

Generally, the change of absorption strength of $1600 \mathrm{~cm}^{-1}$ was not so obvious compared with the other frequencies. The absorption strength of $749 \mathrm{~cm}^{-1}, 810 \mathrm{~cm}^{-1}$, and $871 \mathrm{~cm}^{-1}$ related to the plane deformation vibration of $\mathrm{CH}$ in aromatic ring is correlated with independent, two and more adjacent hydrogen atoms state, respectively. The strongest absorption strength of these frequencies is in the middle metamorphic grade and then in the higher and lower metamorphic grades it is the weakest (Figure 1). Figure 2(b) shows that this change is influenced by brittle and ductile deformation. The strongest absorption strength of $3049 \mathrm{~cm}^{-1}$ related to stretching vibration of $\mathrm{CH}$ in aromatic ring is also in the middle metamorphic grade and gradually decreases towards lower and higher metamorphic grades.

With the increase of deformational intensity (brittle and ductile deformation), the absorption strength of $1600 \mathrm{~cm}^{-1}$ increases at first and then decreases, which is inversed with the variation of absorption strength of $749 \mathrm{~cm}^{-1}$ (Figures $2(\mathrm{c})$ and $2(\mathrm{~d}))$.

\subsubsection{Evolution of Characteristic Frequency of Aliphatic Struc-} ture. The frequency of aliphatic structure includes absorption strength of (1) $2923 \mathrm{~cm}^{-1}$ and $2862 \mathrm{~cm}^{-1}$ related to the asymmetric stretching vibration of $\mathrm{CH}_{2}$ and symmetrical stretching vibration of $\mathrm{CH}_{3}$, shown as shoulder absorption of $2923 \mathrm{~cm}^{-1}$ in aliphatic structure. These frequencies are the weakest in the middle metamorphic grade and increase in the lower and higher metamorphic grades and (2) $1442 \mathrm{~cm}^{-1}$ related to the asymmetric deformation vibration of $\mathrm{CH}_{2}$ and $\mathrm{CH}_{3}$ in alkane structure. With the increase of metamorphic grade, the change of absorption strength of $1442 \mathrm{~cm}^{-1}$ range from 0.8 to 0.99 . 
TABLE 1: Part of experiment results of TDC samples.

\begin{tabular}{lcccccccccccc}
\hline $\begin{array}{l}\text { Series of } \\
\text { deformation }\end{array}$ & Sample ID & $R_{\mathrm{o}, \max } /(\%)$ & $R_{\mathrm{o}, \min } /(\%)$ & $\Delta R_{\mathrm{o}} / R_{\mathrm{o}, \max }{ }^{1}$ & \multicolumn{2}{c}{$\mathrm{CH}_{3} \mathrm{CH}_{2}$} & $\mathrm{C}=\mathrm{C}$ & $\mathrm{CH}_{3} \mathrm{CH}_{2} \mathrm{C}-\mathrm{H}$ & $A_{\mathrm{G}}$ & $A_{\mathrm{D}}$ \\
& & & & & & 2923 & 2826 & 1600 & 1442 & 749 & \\
\hline \multirow{4}{*}{$\begin{array}{l}\text { Brittle deformation } \\
\text { coal }\end{array}$} & LHM06 & 0.98 & 0.83 & 0.15 & 0.557 & 0.326 & 0.991 & 0.815 & 0.317 & 113967 & 55594 \\
& HZM03 & 1.93 & 1.67 & 0.13 & 0.344 & 0.220 & 0.994 & 0.822 & 0.348 & 515720 & 286732 \\
& SK04 & 1.00 & 0.91 & 0.09 & 0.522 & 0.372 & 0.998 & 0.920 & 0.369 & 115158 & 58378 \\
& HZM02 & 1.93 & 1.67 & 0.13 & 0.323 & 0.199 & 0.998 & 0.935 & 0.420 & - & - \\
& LHM12 & 1.37 & 1.13 & 0.18 & 0.579 & 0.383 & 0.998 & 0.933 & 0.385 & 215980 & 131925 \\
& STM02 & 1.41 & 1.12 & 0.21 & 0.647 & 0.403 & 0.994 & 0.806 & 0.380 & 272570 & 153720 \\
& TYM04 & 0.95 & 0.8 & 0.16 & 0.504 & 0.354 & 1.000 & 0.895 & 0.176 & 137498 & 64296 \\
& SK03 & 0.98 & 0.88 & 0.10 & 0.363 & 0.264 & 0.996 & 0.886 & 0.548 & 174251 & 78056 \\
\hline \multirow{5}{*}{$\begin{array}{l}\text { Ductile } \\
\text { deformation coal }\end{array}$} & LHM04 & 1.40 & 1.18 & 0.16 & 0.657 & 0.414 & 0.988 & 0.893 & 0.450 & 394537 & 202143 \\
& LHM09 & 1.39 & 1.12 & 0.19 & 0.599 & 0.406 & 0.996 & 0.951 & 0.362 & - & - \\
& LLM04 & 0.83 & 0.60 & 0.28 & 0.547 & 0.378 & 0.999 & 0.918 & 0.282 & 324725 & 164211 \\
& HZM10 & 2.62 & 2.02 & 0.23 & 0.671 & 0.406 & 0.996 & 0.913 & 0.301 & 461139 & 157064 \\
& LHM02 & 1.38 & 1.08 & 0.22 & 0.582 & 0.38 & 0.998 & 0.946 & 0.385 & - & - \\
& LHM03 & 1.58 & 1.18 & 0.25 & 0.555 & 0.351 & 0.988 & 0.840 & 0.406 & 420961 & 229994 \\
& STM05 & 1.66 & 1.12 & 0.33 & 0.491 & 0.312 & 0.997 & 0.992 & 0.455 & 511926 & 306591 \\
& XTM08 & 1.92 & 1.63 & 0.15 & 0.260 & 0.180 & 1.000 & 0.910 & 0.500 & 499840 & 260745 \\
\hline
\end{tabular}

${ }^{1} \Delta R_{\mathrm{o}}=R_{\mathrm{o}, \max }-R_{\mathrm{o}, \min },{ }^{2}$ The data of Raman was cited in [22].

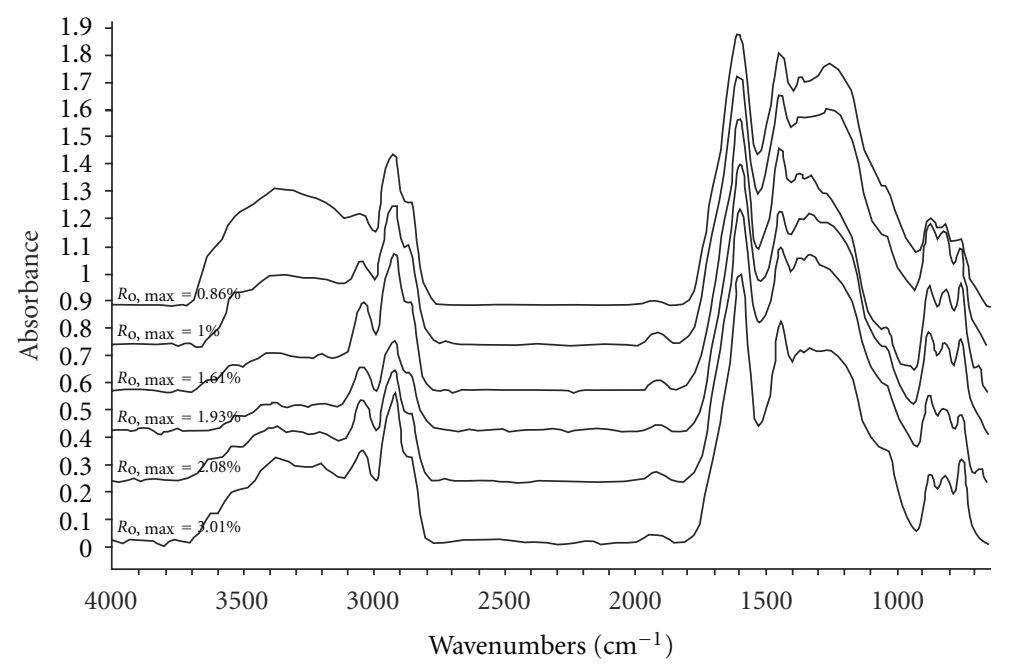

FIGURE 1: The infrared spectrum of TDC with different metamorphic stage.

With the increase of metamorphic grade, the absorption strength of aliphatic structure is much more complicated (Figures 2 and 3). The absorption strength of $2923 \mathrm{~cm}^{-1}$ increases first and then decreases in brittle and ductile deformational coal, but absorption strength change of $1442 \mathrm{~cm}^{-1}$ is not obvious. It is indicated that the aliphatic structure is gradually degraded with the increase of metamorphic grade in these two deformational mechanisms and this results in the decrease of aliphatic structure.

With the increase of deformational intensity, under the lower metamorphism grade, the absorption strength of $2923 \mathrm{~cm}^{-1}$ increases first and decreases later, which is contrary to the absorption strength variation of $1442 \mathrm{~cm}^{-1}$ in brittle and ductile deformational coal (Figures 3(c) and $3(\mathrm{~d})$ ). Under the lower deformational intensity, the aliphatic functional groups, alkane branched chains, and a few aromatic rings break off at first, which promotes the metamorphism because of the brittle deformation. In the meantime, the dropped small moleculars have not got enough time to form aromatic structure because of the rapid strain rate [19-22]. Part of dropped alkane branched chains are transformed into aliphatic functional groups, and others are turned to free macromolecules. Under the slow strain rate of ductile deformational coal [22], the dropped small 


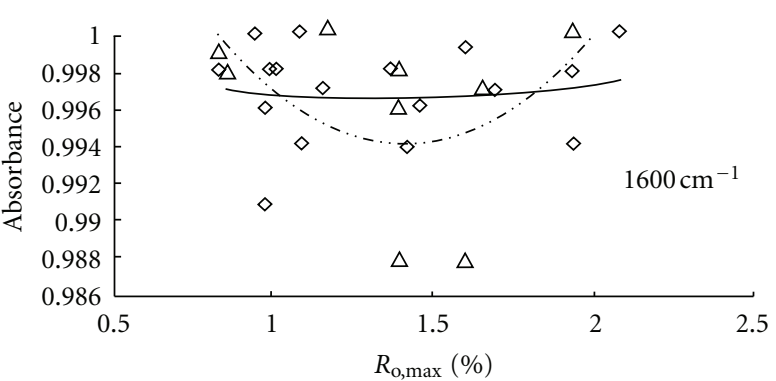

(a)

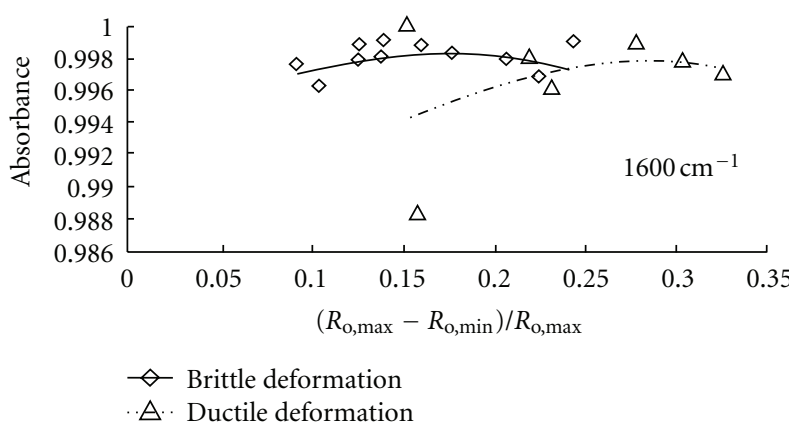

(c)

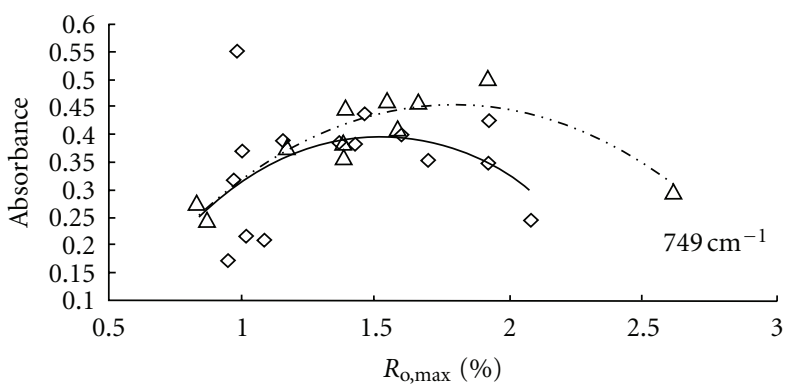

(b)

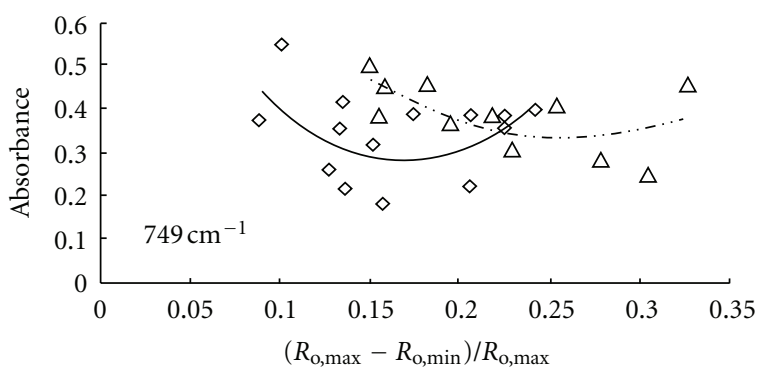

$\diamond$ Brittle deformation

A. Ductile deformation

(d)

FIGURE 2: Relationship of aromatic absorbance peaks of TDC with different metamorphic and deformation stages. (a) and (b) relationship between aromatic absorbance peaks and metamorphic stages. (c) and (d) relationship between aromatic absorbance peaks and deformation stages.

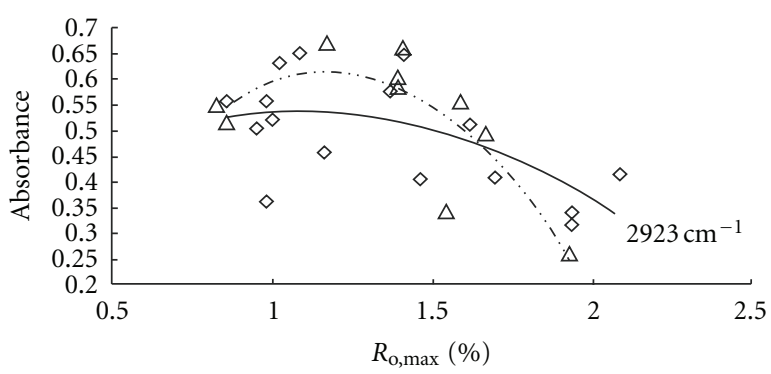

(a)

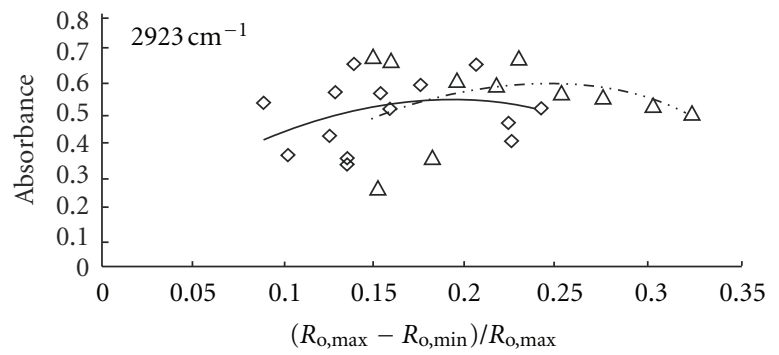

$\diamond$ Brittle deformation

A. Ductile deformation

(c)

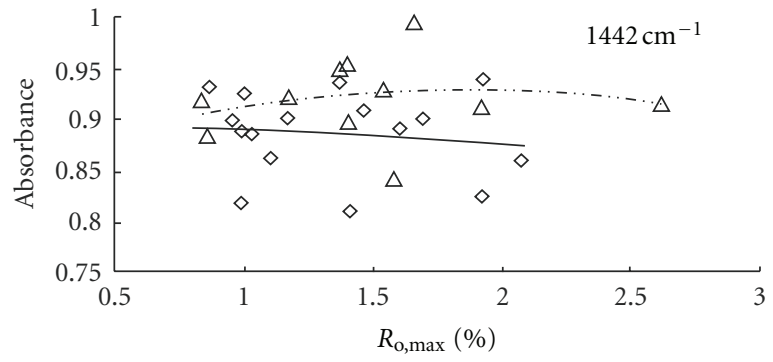

(b)

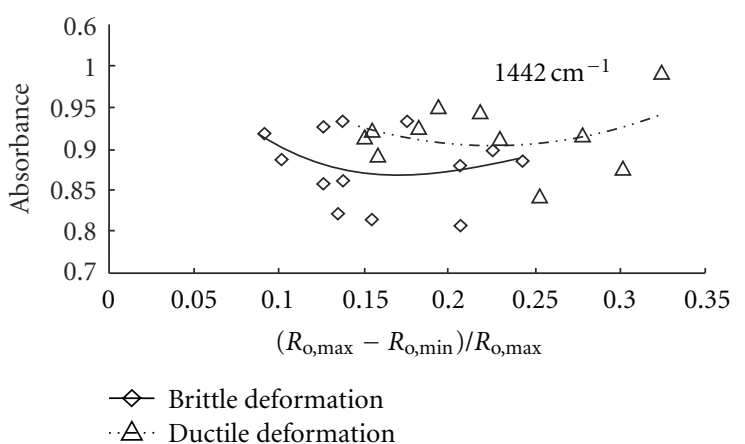

(d)

FIGURE 3: Relationship of aliphatic absorbance peaks of TDC with metamorphic and deformation stages. (a) and (b) relationship between aliphatic absorbance peaks and metamorphic stages. (c) and (d) relationship between aliphatic absorbance peaks and deformation stages. 


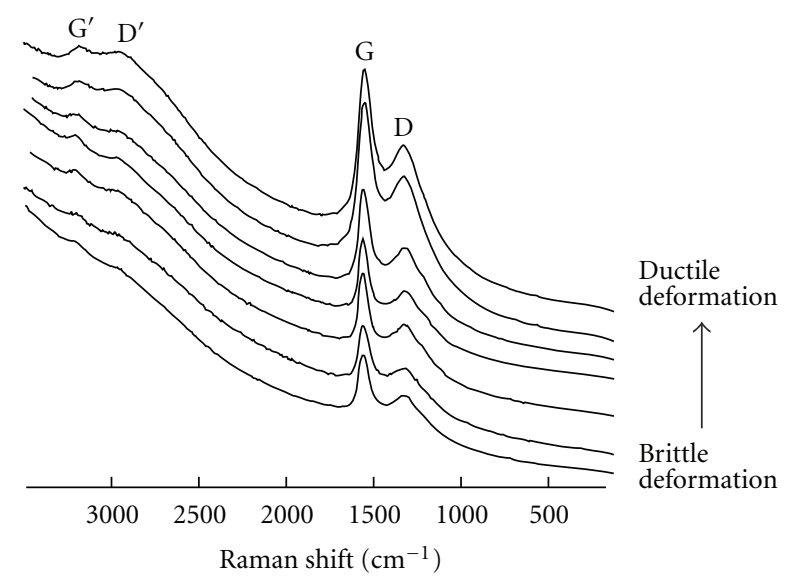

FIGURE 4: The Raman spectrum of TDC with different deformation mechanisms (from [22]).

molecules are combined to aromatic rings and increase the absorption strength of aromatic structure.

3.2. The Raman Spectral Analysis. Nakamizo studied the grinded graphite and graphitized coke applying Raman spectrum and found that the peak $G$ in Raman spectrum is related to the deformation vibration of $\mathrm{C}=\mathrm{C}$ on aromatic plane; the peak area of $G\left(A_{\mathrm{G}}\right)$ stands for the total number of aromatic rings $[24,25]$. The grinding process could form structure defects. It is also suggested that secondary structural defects are produced by exogenic action like grinding process. Previous researchers suggested that the tectonic shear stress process and the grinding process were similar under the geological environment; both could generate secondary structural defects in coal graphite [26].

3.2.1. Evolution of the Peak Area of $G\left(A_{G}\right)$. Two peaks ( $G$ and $D$ ) are observed in Raman spectrum in TDC samples from Huainan-Huaibei coal field, which are in the range from $1590 \mathrm{~cm}^{-1}$ to $1600 \mathrm{~cm}^{-1}$ and the range from $1340 \mathrm{~cm}^{-1}$ to $1356 \mathrm{~cm}^{-1}$, respectively (Figure 4).

Peak $G$ in Raman spectrum is related to the deformational vibration of $\mathrm{C}=\mathrm{C}$ on aromatic plane; $A_{\mathrm{G}}$ means peak area of $G$, the total number of aromatic rings [22, 26]. With the increase of metamorphic grade, forbrittle deformational coal, the values of $A_{\mathrm{G}}$ increase but change gently like a convex curve in ductile deformational coal which is always higher than the values in brittle deformational coal (Figure 5(a)). It is indicated that the total number of aromatic rings increase in brittle deformational coal, but increase first and decrease later in ductile deformational coal when metamorphic grade increases. The FTIR data show that the change of total aromatic rings are relatively slight, but the absorption strength of every frequency band is changed which means that the undulatory property on the whole aromatic structure is caused by fracture, abscission, and cyclization of aliphatic structure in macromolecular structure of coal. With the increase of deformational intensity, the value of $A_{\mathrm{G}}$ increases in brittle deformational coal, but first decreases and then increases in ductile deformational coal (Figure 5). The total number of aromatic rings formed in brittle deformational coal are relatively less than in ductile deformational coal. It is indicated that the ductile deformation played a more important role in the process of polycondensation in macromolecular structure of coal.

3.2.2. Evolution of the Peak Area of $D\left(A_{D}\right)$. The Peak $D$ is related to the lattice vibration of irregular hexagon in disordered $\mathrm{sp}^{2}$ carbonaceous material connected with secondary structural defects between molecular structures $[22,25,26]$. $A_{\mathrm{D}}$ refers to peak area of $D$ and reflects the change of secondary structural defects in the macromolecular structure and the degree of structure order. With the increase of metamorphic grade, the change of $A_{\mathrm{D}}$ is the same as $A_{\mathrm{G}}$. The values of $A_{\mathrm{D}}$ increase in brittle deformational coal, but increase first and then decrease in ductile deformational coal (Figure 6(a)).

Previous research discussed that there were two types in $D$ peak of Raman spectrum; the first one is induced by defects of primary structures $\left(1370 \mathrm{~cm}^{-1}\right)$, and the other is induced by secondary structural defects $\left(1360 \mathrm{~cm}^{-1}\right)$ which are also related to tectonic stress [26]. The peak $D$ in Huaibei TDC samples is all distributed at $1360 \mathrm{~cm}^{-1}$, indicating that the secondary structural defects generated by tectonic stress exist in TDC. With the increase of metamorphic grade, the secondary structural defects increase rapidly in brittle deformational coal, but increase prior to decrease in ductile deformational coal.

With the increase of deformational intensity, the value of $A_{\mathrm{D}}$ increases in brittle deformational coal, but decreases prior to increases in ductile deformational coal (Figure 6(b)). It is suggested that with the increase of deformational intensity, the secondary structural defects increase in brittle deformational coal, but decrease first and then increase in ductile deformational coal. However, the secondary structural defects in brittle deformational coal are always fewer than in ductile deformational coal. The increasing and accumulating of unit dislocation may transform the stress into strain energy in ductile deformational coal $[19,20,22$, 27], which is easier to generate the secondary structural defects in macromolecular structure of TDC.

\section{Discussion}

Compared with primary structure coal $[2-7,16,17,23$, $25,26]$, the difference of macromolecular structure shown by FTIR and Raman data of TDC is obvious with the increase of metamorphic grade. Ju et al. studied the different metamorphism-deformation environments and ultrastructure of various TDC using XRD and Nuclear magnetic resonance methods and observed the ultrastructure directly by High-resolution transmission electron microscope [28, 29]. The results reveal that the temperature and tectonic deformation could affect the metamorphism-deformation environment as shown by the change of the stacking of the basal structural units (BSU) layer $L_{c}$ and the ratio of extension and stacking of the BSU layer $L_{a} / L_{c}$. Under the effect 


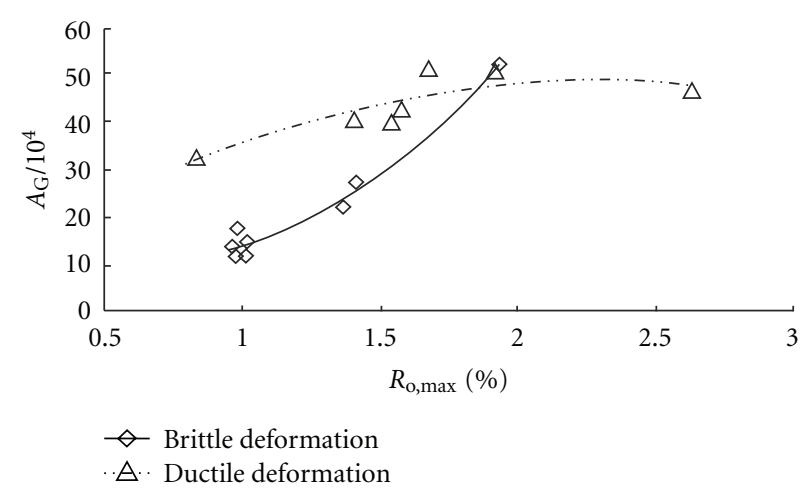

(a)

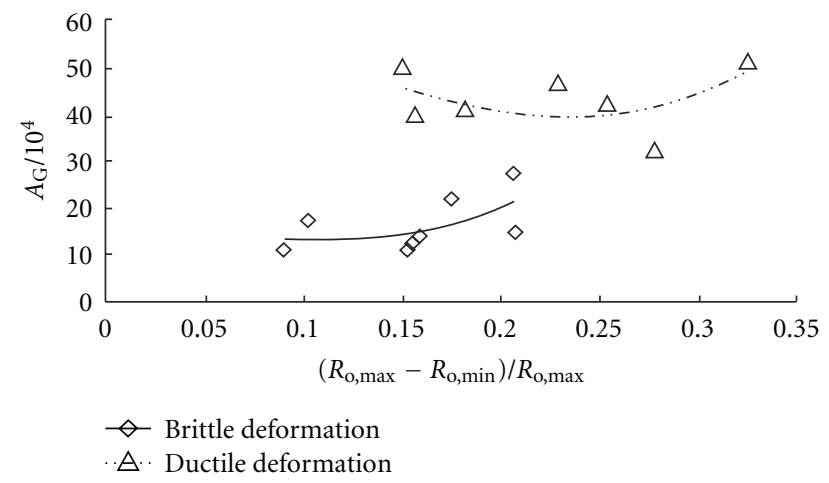

(b)

FIGURE 5: Relationship of $A_{\mathrm{G}}$ of TDC with their metamorphic and deformation stages: (a) relationship between $A_{\mathrm{G}}$ and metamorphic stages, (b) relationship between $A_{\mathrm{G}}$ and deformation stages.

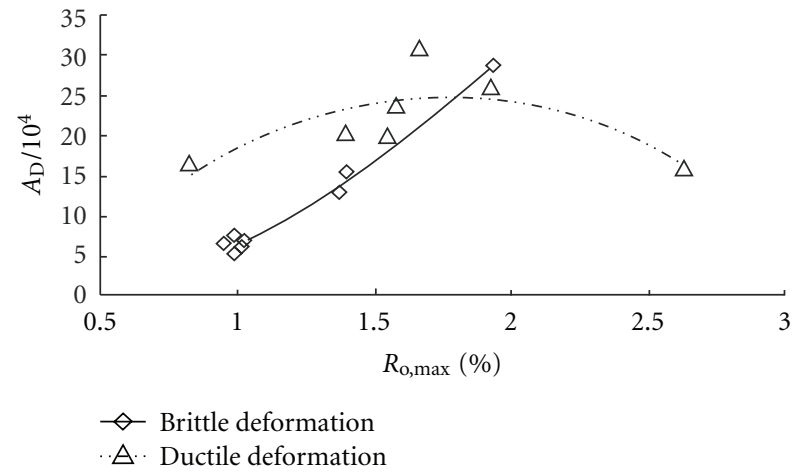

(a)

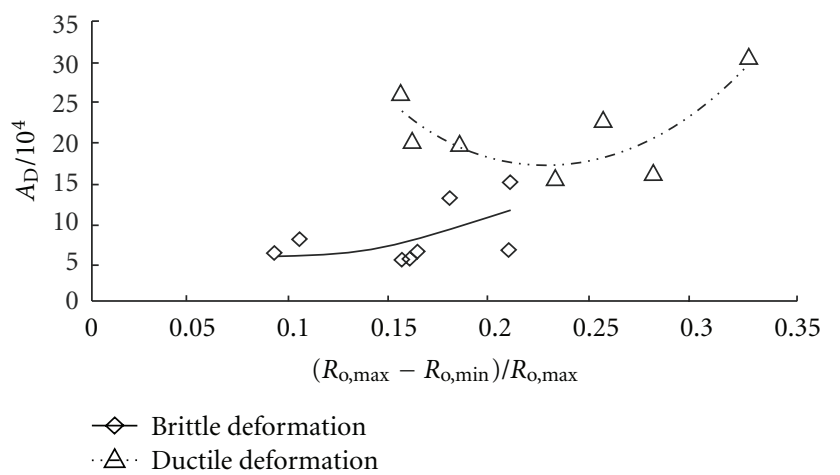

(b)

FIGURE 6: Relationship of $A_{\mathrm{D}}$ of TDC with their metamorphic and deformation stages: (a) relationship between $A_{\mathrm{D}}$ and metamorphic stages, (b) relationship between $A_{\mathrm{D}}$ and deformation stages.

of oriented stress, the orientation of the macromolecular structure becomes locally stronger, and the ordering degree of C-nets as well as the arrangement of the BSU is obviously enhanced. It is suggested that the temperature is not the only reason that results in carbonification process of coal, but also the tectonic deformation plays a very important role in this process $[17,28]$.

With the increase of metamorphic grade, the aliphatic structure and functional groups break off, and the aromatic structure is enriched in ductile deformational coal. However, for brittle deformational coal, the increase of aromatic structure is not obvious. It is indicated that the ductile deformation could produce apparent effect on degradation and polycondensation, and the increased metamorphic grade could promote the ductile deformation and the polycondensation process. The brittle deformation can only produce apparent effect on degradation and has little influence on polycondensation. The absorption strength of aromatic structure is developed as complementary to the aliphatic structure bands compared to the absorption peaks of aromatic and aliphatic structure. In lower metamorphic grade, there is much more aliphatic structures in TDC. Because of the fracture, abscission and cyclization of aliphatic functional groups and alkane branched chains made the aromatic structure increase with the metamorphic grade rise.

With the increase of deformational intensity, the brittle deformation transforms the stress into frictional heat energy $[19,20,22,27]$, increases the kinetic energy, and promotes the degradation. The aliphatic functional groups and alkane branched chains break off first because of the high strain rate, and the residual of them will be transformed into aromatic structure so that the rangeability of aromatic structure in brittle deformation is relatively low. The ductile deformation transforms the stress into strain energy by increasing and accumulating of unit dislocation $[19,20,22,27]$, which promotes the polycondensation. In lower metamorphism stage with degradation as the main reaction, the aliphatic functional groups and alkane branched chains break off by ductile deformation. The dropped small molecules have enough time to form aromatic rings because of the slow strain rate, which results in more and more aromatic structure enrichment in ductile deformational coal.

Raman data show that the $D$ peak of Raman spectrum is observed around $1360 \mathrm{~cm}^{-1}$, indicating that secondary structural defects in TDC samples from Huaibei coal field are induced by tectonic deformation. In lower metamorphic 
grade, the increase of the total number of aromatic rings and secondary structural defects are induced by brittle and ductile deformation, whereas by ductile deformation in higher metamorphic grade. This feature suggests that lower metamorphic grade is a benefit to brittle deformation, while the higher metamorphic grade can promote the ductile deformation. The FTIR spectrum shows that the ductile deformation can produce apparent effect on degradation and polycondensation, but brittle deformation exerts little influence on polycondensation. It is observed that degradation is the main reaction for macromolecular structure formation in lower metamorphic grade, instead of polycondensation in higher metamorphic grade. With the increase of deformational intensity, fewer secondary structural defects exist in brittle deformational coal than in ductile deformational coal, indicating that the ductile deformation can produce the secondary structural defects easier than brittle deformation.

To summarize, different deformational mechanisms change the chemical structure and produce the secondary structural defects, which are the main reason for various structure evolution of TDC compared with primary structure coals. Based on the XRD test about those TDC samples we studied early [29], with the increase of deformational intensity, the degradation is the main effect under brittle deformational coal. The brittle deformation can transform stress into frictional heat energy, increase the kinetic energy, and accelerate the movement of molecule (functional group) $[19,27,29,30]$. The aliphatic functional groups and alkane branched chains break off by brittle deformation and promote the degradation as well, shown by decrease of $L_{c}$ and $L_{a}$. With increasing deformation and accumulating thermal energy, the cyclization and aromatization of aliphatic functional groups increase and form aromatic rings and make the $L_{c}$ and $L_{a}$ increase. Meanwhile, for the ductile deformational coal, the aliphatic functional groups, alkane branched chains, and a fraction of aromatic rings break off by ductile deformational in the lower metamorphism stage shown by the decrease of $L_{c}$. The accumulating of unit dislocation may transform the stress into strain energy and the slow strain rate $[19,27,29,30]$; parts of dropped small molecules have enough time to form aromatic rings and make $L_{a}$ increase. In the higher-middle metamorphism stage, with the polycondensation as the main effect, this promotes more dropped small molecules to form aromatic rings and the polycondensation on the other side. With the increase of ductile deformation and accumulating of unit dislocation, the secondary structural defects are generated in this stage which can reduce the structural stability of TDC. The secondary structural defects make the aliphatic functional groups, alkane branched chains, and a fraction of aromatic rings break off selectivity shown by decrease of $L_{a}$. With more secondary structural defects and small molecules dropped, these small molecules started to fill into secondary structural defects to stabilize the macromolecular structure. So the dropped small molecules splice and embed preferentially in secondary structural defects or residual aromatic structures and form aromatic rings to make the macromolecular structure of much stability.

\section{Conclusions}

(1) With the increase of deformation and metamorphism, the change of FTIR and Raman spectrum shows different ways. The tectonic deformation made a very important role which affects the macromolecular structure of TDC. Different deformational mechanism induced different evolution process of macromolecular structure of TDC. The ductile deformation can produce apparent effect on degradation and polycondensation, but brittle deformation has little influence on polycondensation in lower metamorphic grade. In higher metamorphic grade, polycondensation is the main reaction in macromolecular structure of coal. It means that the degradation is the main effect under brittle deformation and the polycondensation under ductile deformation.

(2) Tectonic dmaineformation can produce the secondary structural defects in macromolecular structure of TDC. The increase of total number of aromatic rings and secondary structural defects is mainly caused by brittle deformation in lower metamorphic grade, but ductile deformation in higher metamorphic grade. Furthermore, the ductile deformation can produce the secondary structural defects easier than brittle deformation.

(3) The existence of secondary structural defects reduces the stability of macromolecular structure in TDC. Brittle deformation promotes the degradation and makes the aliphatic functional groups and alkane branched chains break off selectively in lower metamorphic grade. With the increase of deformation and metamorphism, more secondary structural defects are produced and small molecules are dropped; the ductile deformation promotes the polycondensation, so the dropped small molecules splice and embed preferentially in secondary structural defects or residual aromatic structures and form aromatic rings to make the macromolecular structure of much stability.

\section{Acknowledgments}

This work is supported by the National Natural Science Foundation of China (Grants nos. 40772135, 40972131, and 41030422), the National Basic Research Program of China (Grants nos. 2009CB219601 and 2006CB202201), and the Strategic Priority Research Program of the Chinese Academy of Sciences (XDA05030100).

\section{References}

[1] J. R. Levine and A. Davis, "The relationship of coal optical fabrics to alleghanian tectonic deformation in the central Appalachian fold-and-thrust belt," Pennsylvania Geological Society of America Bulletin, vol. 101, no. 10, pp. 1333-1347, 1989.

[2] D. Y. Cao, S. R. Zhang, and D. Y. Ren, "The influence of structural deformation on coalification: a case study of 
carboniferous coal measures in the Northern foothills of the dabie orogenic belt," Geological Review, vol. 48, no. 3, pp. 313$317,2002$.

[3] D. J. Zhang and X. F. Xian, "I.R. spectroscopy analysis of the groups in coal macromolecule," Journal of Chongqing University, vol. 13, no. 5, pp. 6-7, 1990.

[4] X. D. Zhu, Z. B. Zhu, and C. J. Han, "Quantitative determination of oxygen-containing functional groups in coal by FTIR spectroscopy," Journal of Fuel Chemistry and Technology, vol. 27, no. 4, pp. 335-339, 1999.

[5] J. Ibarra, E. Muñoz, and R. Moliner, "FTIR study of the evolution of coal structure during the coalification process," Organic Geochemistry, vol. 24, no. 6-7, pp. 725-735, 1996.

[6] Y. W. Ju, B. Jiang, G. L. Wang et al., Tectonically Deformed Coals: Structure and Physical Properties of Reservoirs, China University of Mining and Technology Press, Xuzhou, China, 2005.

[7] Y. W. Ju, B. Jiang, Q. L. Hou, and G. L. Wang, "FTIR spectroscopic study on the stress effect of compositions of macromolecular structure in tectonically deformed coals," Spectroscopy and Spectral Analysis, vol. 25, no. 8, pp. 12161220, 2005.

[8] J. Jehlička, O. Urban, and J. Pokorný, "Raman spectroscopy of carbon and solid bitumens in sedimentary and metamorphic rocks," Spectrochimica Acta A, vol. 59, no. 10, pp. 2341-2352, 2003.

[9] C. P. Marshall, E. J. Javaux, A. H. Knoll, and M. R. Walter, "Combined micro-Fourier transform infrared (FTIR) spectroscopy and micro-Raman spectroscopy of proterozoic acritarchs: a new approach to Palaeobiology," Precambrian Research, vol. 138, no. 3-4, pp. 208-224, 2005.

[10] S. Bernard, O. Beyssac, K. Benzerara, N. Findling, G. Tzvetkov, and G. E. Brown, "XANES, Raman and XRD study of anthracene-based cokes and saccharose-based chars submitted to high-temperature pyrolysis," Carbon, vol. 48, no. 9, pp. 2506-2516, 2010.

[11] A. Cuesta, P. Dhamelincourt, J. Laureyns, and J. M. D. Tascón, "Comparative performance of X-ray diffraction and Raman microprobe techniques for the study of carbon materials," Journal of Materials Chemistry, vol. 8, pp. 2875-2879, 1998.

[12] O. Beyssac, L. Bollinger, J. P. Avouac, and B. Goffé, "Thermal metamorphism in the lesser Himalaya of Nepal determined from Raman spectroscopy of carbonaceous material," Earth and Planetary Science Letters, vol. 225, no. 1-2, pp. 233-241, 2004.

[13] J. Jehlička, O. Urban, and J. Pokorný, "Raman spectroscopy of carbon and solid bitumens in sedimentary and metamorphic rocks," Spectrochimica Acta A, vol. 59, no. 10, pp. 2341-2352, 2003.

[14] J. Jehlička and C. Beny, "First and second order Raman spectra of natural highly carbonified organic compounds from metamorphic rocks," Journal of Molecular Structure, vol. 480481, pp. 541-545, 1999.

[15] O. Urban, J. Jehlička, J. Pokorný, and J. N. Rouzaud, “Influence of laminar flow on preorientation of coal tar pitch structural units: Raman microspectroscopic study," Spectrochimica Acta A, vol. 59, no. 10, pp. 2331-2340, 2003.

[16] Y. Qin, Micropetrology and Structural Evolution of HighRank Coals in P. R. China, China University of Mining and Technology Press, Xuzhou, China, 1994.

[17] Y. W. Ju and X. S. Li, "New research progress on the ultrastructure of tectonically deformed coals," Progress in Natural Science, vol. 19, no. 11, pp. 1455-1466, 2009.
[18] Y. W. Ju, B. Jiang, Q. L. Hou, and G. L. Wang, "The new structure-genetic classification system in tectonically deformed coals and its geological significance," Journal of China Coal Society, vol. 29, no. 5, pp. 513-517, 2004.

[19] Y. W. Ju, G. L. Wang, B. Jiang, and Q. Hou, "Microcosmic analysis of ductile shearing zones of coal seams of brittle deformation domain in superficial lithosphere," Science in China D, vol. 47, no. 5, pp. 393-404, 2004.

[20] Y. W. Ju, H. Lin, X. S. Li et al., "Tectonic deformation and dynamic metamorphism of coal," Earth Science Frontiers, vol. 16, no. 1, pp. 158-166, 2009.

[21] D. Y. Cao, X. M. Li, and S. R. Zhang, "Influence of tectonic stress on coalification: stress degradation mechanism and stress polycondensation mechanism," Science in China D, vol. 50, no. 1 , pp. 43-54, 2007.

[22] H. Lin, Y. W. Ju, Q. L. Hou et al., "Raman spectra of tectonically deformed coals in brittle and ductile deformation mechanisms and its response to structural components," Progress in Natural Science, vol. 19, no. 10, pp. 1117-1125, 2009.

[23] D. J. Zhang and X. F. Xian, "The study of the macromolecular structure of coal by FTIR spectroscopy," Spectroscopy and Spectral Analysis, vol. 9, no. 3, pp. 17-19, 1989.

[24] M. Nakamizo, R. Kammereck, and P. L. Walker Jr., "Laser Raman studies on carbons," Carbon, vol. 12, no. 3, pp. 259267, 1974.

[25] M. F. Li, F. G. Zeng, F. H. Qi, and B. L. Sun, "Raman spectroscopic characteristics of different rank coals and the relation with XRD structural parameters," Spectroscopy and Spectral Analysis, vol. 29, no. 9, pp. 2446-2449, 2009.

[26] Z. Zheng and X. H. Chen, "Raman spectra of coal-based graphite," Science in China B, vol. 38, no. 1, pp. 97-106, 1995.

[27] Q. L. Hou, J. L. Li, S. Sun et al., "Discovery and mechanism discussion of supergene micro-ductile shear zone," Chinese Science Bulletin, vol. 40, no. 10, pp. 824-827, 1995.

[28] Y. W. Ju, B. Jiang, Q. L. Hou, G. Wang, and S. Ni, " ${ }^{13}$ C NMR spectra of tectonic coals and the effects of stress on structural components," Science in China D, vol. 5, no. 9, pp. 847-861, 2005.

[29] X. S. Li, Y. W. Ju, Q. L. Hou et al., "Structural response to deformation of the tectonically deformed coal macromolecular," Acta Geologica Sinica (English Eition), In press, 2012.

[30] Q. L. Hou and D. L. Zhong, "The deformation and metamorphism in the wuliangshan ductile shear zone in Western Yunnan, China," in Memoir of Lithospheric Tectonic Evolution Research, pp. 24-29, Seismology Press, Beijing, China, 1st edition, 1993. 

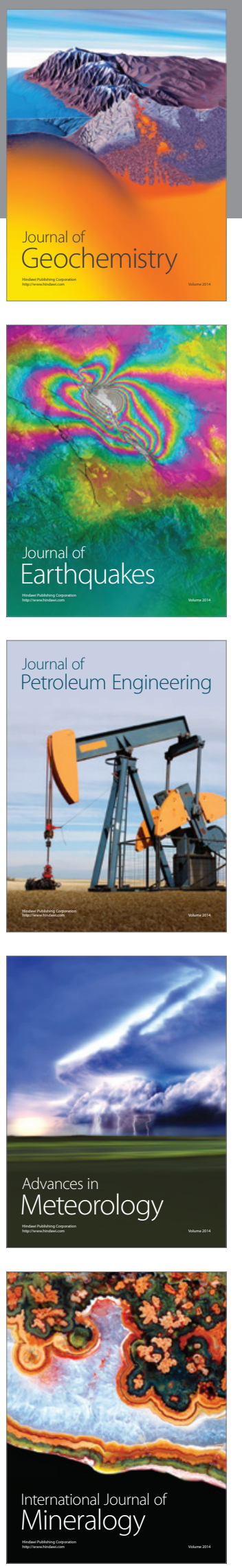
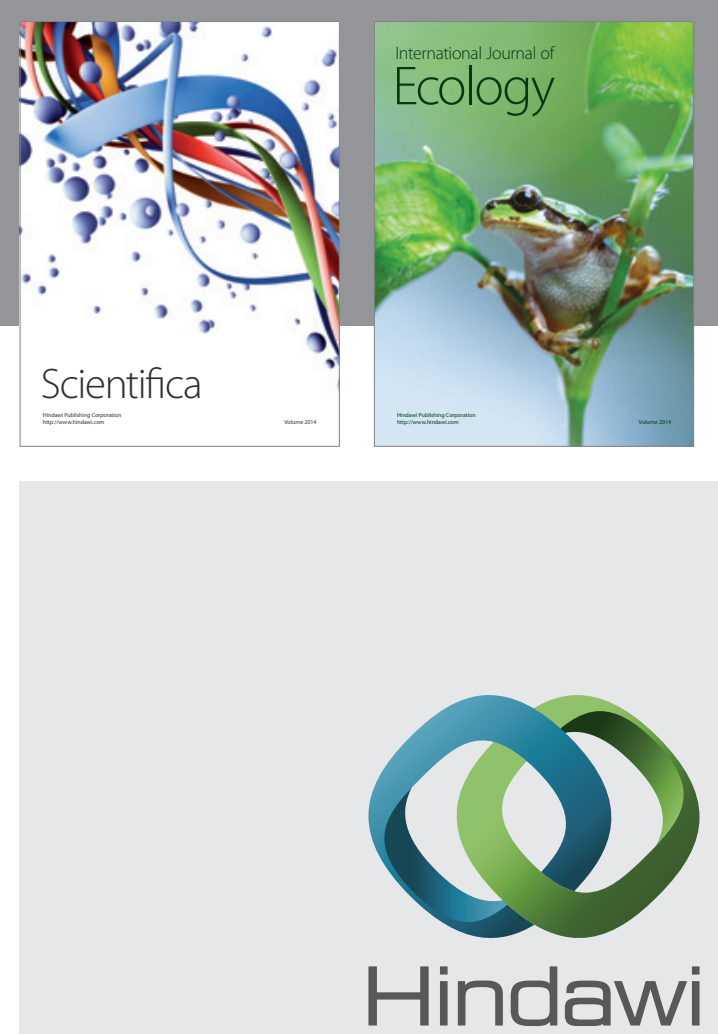

Submit your manuscripts at http://www.hindawi.com
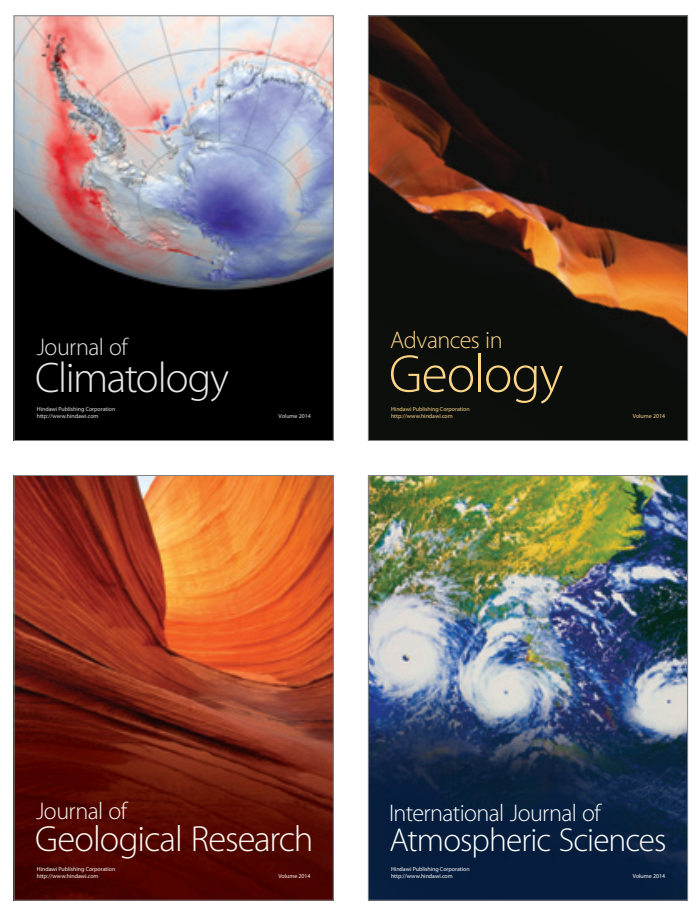
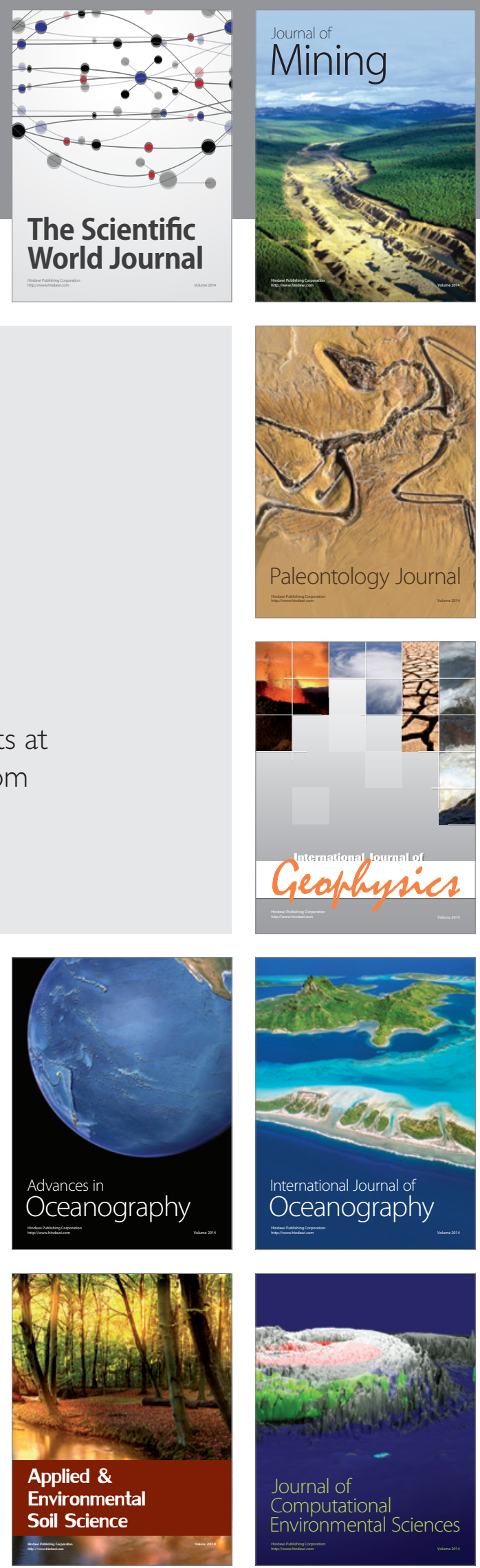